\title{
La internacionalización de la UAA a través de las TIC
}

Raúl Arias Ulloa

\section{Resumen}

$\mathrm{A}$ 45 años de la creación de la Universidad Autónoma de Aguascalientes [UAA], ésta ha transitado por una transformación continua, logrando posicionarse, en este momento, a nivel nacional por la calidad de sus programas educativos y de sus egresados. Sin embargo, las circunstancias actuales de globalización en todos los ámbitos, incluyendo las tecnologías de la información y la comunicación que ponen al alcance de todo mundo los servicios educativos, hacen necesario plantear el objetivo de comenzar la internacionalización de la institución mediante la oferta de cursos a través de estas tecnologías, aprovechando la experiencia con que ya cuenta la Universidad en este campo.

Palabras clave: TIC, educación superior, internacionalización.

\section{Introducción}

La UAA se creó en el año 1973. A la fecha, ha logrado consolidarse a nivel estatal y regional por la calidad de sus programas educativos y de sus egresados, ofertando una diversidad de carreras a nivel licenciatura y posgrado que satisfacen las necesidades sociales en esos ámbitos; además, tiene como uno de sus fines la investigación científica y tecnológica, principalmente ligadas a los programas de posgrado. Sin embargo, su acercamiento a otras instituciones de educación superior (IES) del extranjero es poco, y su oferta a estudiantes de otras latitudes del mundo es casi nula.

La globalización que se ha dado en todos los campos del quehacer humano también ha impactado a la educación superior; así, la "masificación" de la educación se ha convertido en un reto para las autoridades educativas del mundo entero. Esto ha dado lugar al término "mundialización", que la Organización de las Naciones Unidas para la Educación, la Ciencia y la Cultura [UNESCO] define como "la realidad que conforman una economía mundial cada vez más integrada, la nueva tecnología de la información y la comunicación [TIC], la aparición de una red internacional de conocimientos, el papel del idioma inglés y otras fuerzas que escapan al control de las instituciones académicas" (Altbach, Reisberg y Rumbley, 2009). La mundialización (Gacel, 2000) ha generado la necesidad de "internacionalización" de las instituciones de educación superior, entendiendo ésta como:

La multiplicidad de políticas y programas que las universidades y las autoridades públicas ponen en práctica frente a la mundialización, consistentes normalmente en enviar a alumnos a cursar estudios en el extranjero, establecer campus filiales en otros países o entablar algún tipo de relación de asociación interinstitucional (Altbach, Reisberg y Rumbley, 2009: 2).

La propia UNESCO priorizó, en forma operativa, tres áreas de trabajo en educación superior en donde se propone apoyar a los países miembros (Didou, 2014):

a. Vinculada con la internacionalización. Ofrece apoyo técnico para la puesta en operación y evaluación de los instrumentos de reconocimiento de créditos y títulos obtenidos en el extranjero y para el mejoramiento de los sistemas de acreditación y evaluación.

b. Relacionada con el uso de las tecnologías para el suministro de servicios de educación superior. Propone analizar programas de educación a distancia con buenas prácticas y asesorar a los estados miembros en su desarrollo, para ampliar la oferta de programas en educación superior virtual.

c. Concerniente al apoyo a las políticas. Apoyo para proveer información y recomendaciones sobre temas torales como la equidad, la calidad, la diversificación de la educación superior, la gobernanza en las IES y el financiamiento. 
La globalización de prácticamente todos los quehaceres del ser humano obliga a las IES a ir acorde con ello; en el Cuadro 1 se muestran las características de los modelos para la internacionalización de las IES. Se puede observar en los cinco modelos anteriores que la internacionalización de las IES requiere cumplir con procesos en diferentes etapas de desarrollo, por lo que sería imposible sostener que ésta se pueda dar de inmediato en los diferentes ámbitos (currículo flexible, convalidación de títulos, movilidad estudiantil, uso de las TIC, etcétera).

Lo que sí es cierto es que la UAA no puede quedar atrás en este proceso, por lo que es necesario implementar medidas para lograr en el mediano plazo su internacionalización. Si se analizan sus documentos normativos, se puede concluir que ya tiene fincadas las bases para lograrlo, es cuestión de ponerse a trabajar en su implementación. El Plan de Desarrollo Institucional 2016-2024 (UAA, 2016) se plantea en su misión y visión la internacionalización de la Institución para el año 2024, acorde con su Modelo Educativo Institucional (UAA, 2007) en sus cinco componentes.

Como se menciona líneas arriba, sería imposible lograr la internacionalización de la UAA de forma inmediata, por lo que es conveniente incursionar en alguno de los ámbitos considerados pertinentes para la Institución. Ese nicho de oportunidad podría ser el uso de las TIC, ligadas primordialmente al posgrado en una primera etapa, posteriormente se ampliaría para el pregrado, aprovechando la experiencia obtenida.

El aprovechamiento de las TIC para impartir cursos en línea de posgrado e, incluso, posgrados completos en esta modalidad virtual, tendría las siguientes ventajas:

1. Aprovechamiento óptimo de la plataforma virtual con que cuenta la UAA.

2. Aprovechamiento de la planta docente que ya cuenta con el dominio del idioma inglés.

3. Diversificación de las líneas de investigación científica e incursión en redes nacionales e internacionales.

4. Incremento de los ingresos propios de la institución, al aumentar la cobertura y diversificación de los programas de posgrado.

5. Bajo costo en su implementación y desarrollo.

6. Mayor competitividad con otras IES de la región y el país.

7. Consolidación de la UAA en el ámbito regional, nacional e internacional.

Es importante mencionar que la Institución tiene ya experiencia en este campo, como lo demuestran los posgrados consolidados y reconocidos por el Consejo Nacional de Ciencia y Tecnología [CONACyT], diversos diplomados,

Cuadro 1. Características de los modelos para la internacionalización de las IES

\begin{tabular}{|c|c|c|c|c|}
\hline $\begin{array}{l}\text { Warner } \\
\text { (1992) }\end{array}$ & $\begin{array}{l}\text { Knight } \\
\text { (1994) }\end{array}$ & $\begin{array}{l}\text { Davis } \\
\text { (1994) }\end{array}$ & $\begin{array}{l}\text { Rudzki } \\
\text { (1998) }\end{array}$ & Van der Wende (2002) \\
\hline $\begin{array}{c}\text { Modelo 1) competitividad } \\
\text { internacional: elementos y } \\
\text { características específicas } \\
\text { en el currículo que le den } \\
\text { al estudiante un mejor } \\
\text { posicionamiento en el mercado } \\
\text { laboral. } \\
\text { Modelo 2) la } \\
\text { internacionalización como un } \\
\text { modelo de autodesarrollo: } \\
\text { contribuye a que los fenómenos } \\
\text { de la globalización se entiendan } \\
\text { como un proceso de apertura } \\
\text { comercial en las fronteras. } \\
\text { Modelo 3) transformación } \\
\text { social: el conocimiento } \\
\text { adquirido por los estudiantes } \\
\text { contribuye en el proceso de } \\
\text { transformación social de sus } \\
\text { regiones. }\end{array}$ & $\begin{array}{l}\text { Modelo compuesto por } \\
\text { seis etapas: } \\
\text { a) toma de conciencia de } \\
\text { los actores; } \\
\text { b) la etapa del } \\
\text { compromiso institucional; } \\
\text { c) la etapa de planeación } \\
\text { de las actividades; } \\
\text { d) la etapa operativa } \\
\text { está preparada en sus } \\
\text { funciones; } \\
\text { e) durante la etapa } \\
\text { de evaluación de los } \\
\text { procesos administrativos; } \\
\text { y } \\
\text { f) la etapa de } \\
\text { reforzamiento del } \\
\text { proceso. }\end{array}$ & $\begin{array}{c}\text { Modelo compuesto por } \\
\text { dos ejes: } \\
\text { Eje 1. Las IEs actúan } \\
\text { de forma reactiva, } \\
\text { esporádica e irregular } \\
\text { en sus actividades y } \\
\text { programas. } \\
\text { Eje 2. Las IEs poseen y } \\
\text { aplican procedimientos } \\
\text { precisos y diseñados } \\
\text { específicamente para } \\
\text { las actividades de la } \\
\text { internacionalización. }\end{array}$ & $\begin{array}{c}\text { Modelo de planeación } \\
\text { estratégica compuesto } \\
\text { por cuatro actividades: } \\
\text { Actividad 1. El cambio } \\
\text { organizativo. } \\
\text { Actividad 2. La } \\
\text { innovación del } \\
\text { currículo. } \\
\text { Actividad 3. El } \\
\text { desarrollo de recursos } \\
\text { humanos. } \\
\text { Actividad 4. La } \\
\text { movilidad estudiantil. }\end{array}$ & $\begin{array}{l}\text { Se considera el corto } \\
\text { y largo plazos en los } \\
\text { efectos. } \\
\text { Los beneficios a } \\
\text { corto plazo recaen } \\
\text { en el estudiante, } \\
\text { el académico y en } \\
\text { las prácticas de } \\
\text { docencia; mientras } \\
\text { que los beneficios } \\
\text { a largo plazo son } \\
\text { acumulativos para las } \\
\text { IEs, por incrementar } \\
\text { la calidad de la } \\
\text { educación, mejorar el } \\
\text { perfil de los egresados } \\
\text { y obtener un mejor } \\
\text { posicionamiento } \\
\text { institucional. }\end{array}$ \\
\hline
\end{tabular}


cursos de educación continua, de formación de profesores y de nivelación de licenciatura, entre otros; todos ellos utilizando la plataforma en línea. Esta experiencia debería aprovecharse para planear el lanzamiento de la internacionalización de la UAA a través de las TIC.

En resumen, la UAA puede comenzar su proceso de internacionalización al instrumentar las siguientes acciones:

1. Capacitar al personal docente y administrativo de apoyo en el uso de las TIC.

2. Fomentar el uso de las tic para el desarrollo de cursos, principalmente en el posgrado.

3. Establecer convenios de colaboración con universidades nacionales y extranjeras para el desarrollo de recursos humanos que apoyen a los posgrados de calidad mediante el uso de las TIC, procurando, incluso, en los egresados la doble titulación.

4. Fomentar el desarrollo de un segundo idioma (preferentemente inglés) entre el profesorado y personal administrativo de apoyo en el manejo de las TIC.

\section{Conclusión}

El mundo globalizado en que vivimos y la masificación de la educación superior obligan a las IES a estar acorde con este orden mundial, por lo que la internacionalización es imprescindible si se quiere estar vigente en el contexto mundial. Para nuestra Institución es imposible lograrlo en todos los ámbitos en el corto plazo, por lo que el aprovechamiento de las TIC podría llevarla a incursionar en la interna- cionalización de sus programas educativos; primeramente los posgrados y, posteriormente, en el pregrado.

\section{Fuentes de consulta}

Altbach, P. G., Reisberg, L. y Rumbley, L. E. (2009). Tras la pista de una revolución académica: Informe sobre las tendencias actuales. Conferencia mundial sobre la educación superior. UNESCO-Conferencia Mundial sobre la Educación Superior 2009. Consultado en: https://bit. ly/2J3K5N6.

Didou, A. S. (2014). La unEsCo y la educación superior, 20142017: aportes de la reunión de cátedras UNESCO sobre la educación superior, las TIC en la educación y los profesores. Recuperado de: https://bit.ly/2PGzHxB.

Gacel, J. (2000). La dimensión internacional de las universidades mexicanas. Revista de la Educación Superior, 29(115), 1-12.

Moctezuma, P. y Navarro, A. (2011). Internacionalización de la educación superior: aprendizaje institucional en Baja California. Revista de Educación Superior, XL(3) (159), 47-66. Recuperado de: https://bit.ly/2CNzvK1.

UAA (2007). Modelo Educativo Institucional. Correo Universitario, séptima época, No. 15. [Primera reimpresión] 29 de mayo de 2015. México: Universidad Autónoma de Aguascalientes. Consultado en: https://bit. ly/2OrlYxX.

UAA (2016). Plan de Desarrollo Institucional 2016-2024. México: Universidad Autónoma de Aguascalientes. Recuperado de: http://pdi.uaa.mx/.

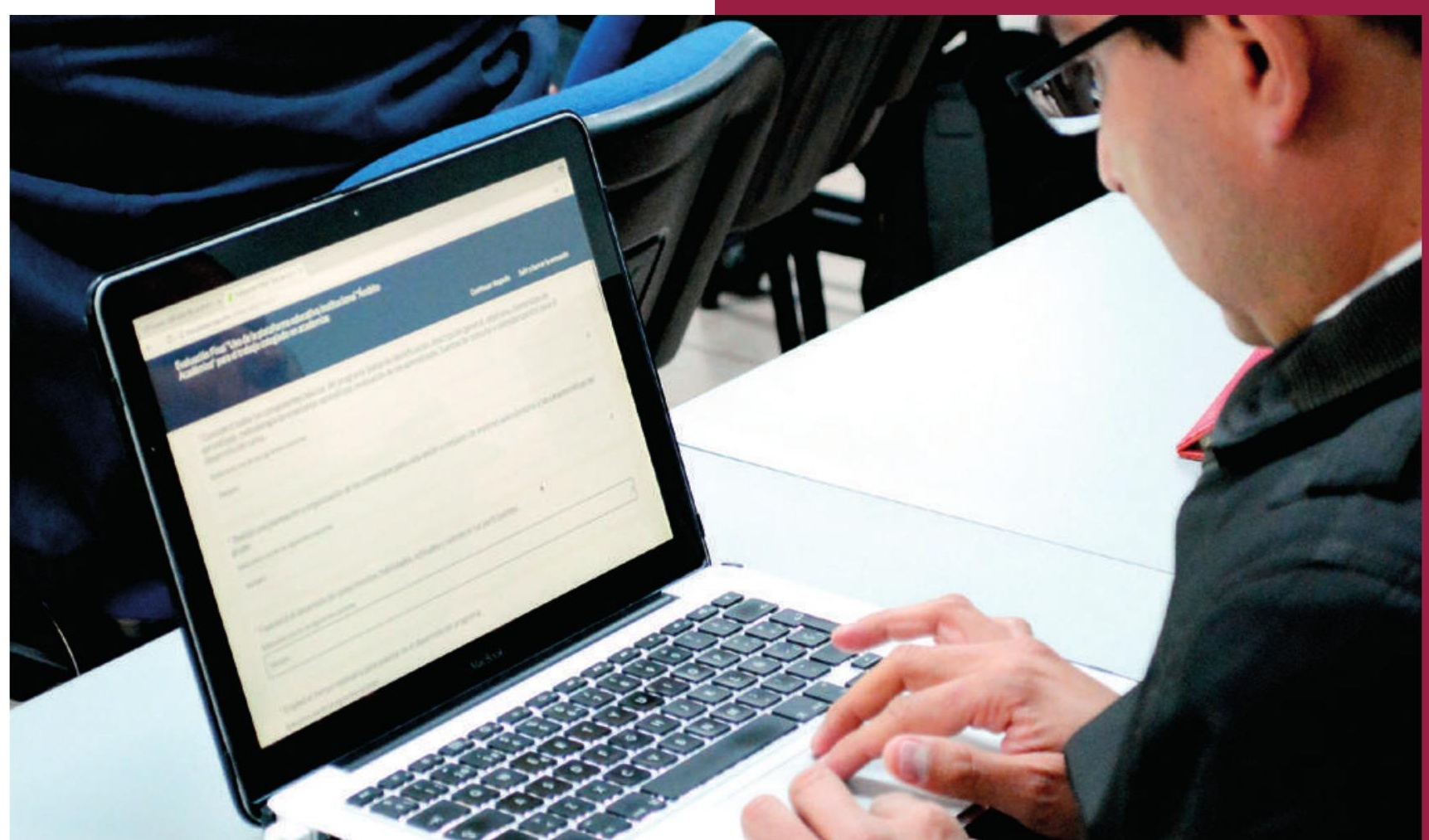

